\title{
EFEKTIVITAS MODEL PEMBELAJARAN TEAM ASSISTED INDIVIDUALIZATION (TAI) TERHADAP KEMAMPUAN PEMECAHAN MASALAH MATEMATIKA SISWA KELAS VIII SMP
}

\author{
Sri Utami , Lalu Sucipto \\ 1Pendidikan Matematika, UIN Mataram, ciptobajok@gmail.com
}

\begin{tabular}{l} 
INFO ARTIKEL \\
\hline RiwayatArtikel: \\
Diterima: $12-09-2017$ \\
Disetujui: $30-09-2017$
\end{tabular}

Kata Kunci:

Efektivitas

Model TAl

Pemecahan Masalah

\begin{abstract}
ABSTRAK
Abstrak - Penelitian ini bertujuan untuk mengetahui keefektifan model pembelajaran Team Assisted Individualization (TAI) terhadap kemampuan pemecahan masalah matematika siswa. Populasi dalam penelitian ini adalah siswa kelas VIII SMP Salafiyah Darul Falah Mataram yang berjumlah 153 siswa. Sampel dalam penelitian ini yaitu kelas VIII B dengan jumlah 28 siswa. Jenis penelitian yang digunakan adalah penelitian kuantitatif, dengan desain pre-eksperimen (One Group Pretest Postest Design). Teknik pengambilan sampel yaitu menggunakan teknik cluster random sampling . Teknik analisis data menggunakan uji-t test Sampel Related. Hasil perhitungan uji-t tes Sampel Related didapatkan $t_{\text {hitung }}$ sebesar 19,01dan $t_{\text {tabel }}$ sebesar 2,052 dengan taraf signifikan $5 \%$. Karena $t_{\text {hitung }} \geq t_{\text {tabel }}$, maka menunjukkan bahwa model pembelajaran Team Assisted Individualization (TAI) efektif terhadap kemampuan pemecahan masalah matematika siswa.
\end{abstract}

\begin{abstract}
This study aims to determine the effectiveness of Teachers Assisted Individualization (TAI) learning model for students' math problem solving skills. The population in this study is the students of grade VIII SMP Salafiyah Darul Falah Mataram, amounting to 153 students. The sample in this research is class VIII B with the number of 28 students. The type of research used is quantitative research, with preexperiment design (One Group Pretest Postest Design). The sampling technique is using cluster random sampling technique. Technique of data analysis using test-t test Sampel Related. The result of $t$-test calculation of Sample Related test obtained t_hitung equal to 19,01 and t_table equal to 2,052 with significant level 5\%. Because t_hitung $\geqslant t$ t_tabel, then show that Team Assisted Individualization (TAI) learning model effective to student's math problem solving ability.
\end{abstract}

\section{A. PENDAHULUAN}

Kemampuan dalam penyelesaian masalah sangat diperlukan dalam kehidupan. Kemampuan pemecahan masalah menuntut seseorang untuk berpikir kritis, logis, dan kreatif yang sangat berguna dalam menghadapi perkembangan zaman yang semakin rumit. Kemampuan pemecahan masalah juga penting dalam dunia pendidikan, khususnya dalam mata pelajaran Matematika.

Berdasarkan Permendiknas Nomor 22 tahun 2006 tentang Standar Isi (SI) mata pelajaran, Standar Isi Mata Pelajaran Matematika untuk semua jenjang pendidikan dasar dan menengah dinyatakan bahwa tujuan mata pelajaran Matematika di sekolah adalah agar siswa mampu: 1) Memahami konsep Matematika, menjelaskan keterkaitan antar konsep dan mengaplikasikan konsep algoritma secara luwes, akurat, efisien, dan tepat dalam pemecahan masalah;
2) Menggunakan penalaran pada pola dan sifat, melakukan manipulasi matematika dalam membuat generalisasi, menyusun bukti, atau menjelaskan gagasan dan pernyataan matematika; 3) Memecahkan masalah yang meliputi kemampuan memahami masalah, merancang model matematika, menyelesaikan model, dan menafsirkan solusi yang diperoleh; 4) Mengkomunikasikan gagasan dengan simbol, tabel, diagram, atau media lain untuk memperjelas keadaan atau masalah; 5) Memiliki sikap menghargai kegunaan Matematika dalam kehidupan, yaitu memiliki rasa ingin tahu, perhatian, dan minat dalam mempelajari Matematika, serta sikap ulet dan percaya diri dalam pemecahan masalah (Sri Wardhani, 2008: 2).

Berdasarkan tujuan pembelajaran Matematika di atas, salah satu kemampuan penting yang harus dimiliki oleh siswa adalah kemampuan siswa dalam memecahkan masalah Matematika. Mengingat pentingnya kemampuan pemecahan masalah, sehingga hampir di semua Standar 
Kompetensi dan Kompetensi Dasar dijumpai penegasan diperlukannya kemampuan pemecahan masalah. Karena pentingnya pemecahan masalah tersebut, maka sudah sewajarnya jika pemecahan masalah diberikan kepada siswa agar mampu menyelesaikan permasalahan Matematika.

Pada umumnya kesulitan memecahkan masalah Matematika yang dialami oleh siswa berbeda-beda tergantung pada kemampuan siswa itu sendiri dalam memecahkannya. Selain itu guru Matematika diharapkan menggunakan masalah Matematika yang berbentuk uraian jika dibandingkan dengan menggunakan masalah berbentuk pilihan ganda, hal ini dikarenakan masalah berbentuk uraian dapat menumbuhkan kemampuan berpikir kritis, logis, dan sistematis (Sri Adi Widodo, 2016: 128).

Observasi awal yang dilakukan oleh peneliti di kelas VIII SMP Salafiyah Darul Falah, proses pembelajaran Matematika di kelas masih didominasi oleh guru. Hal ini terlihat pada saat berlangsungnya kegiatan pembelajaran, terlihat aktivitas siswa yang hanya mencatat dan menyalin. Ketika guru memberikan soal yang terkait pemecahan masalah, sebagian siswa bingung dan tidak segera menyelesaikan soal yang diberikan, namun yang dilakukan hanya asal-asalan dalam mengerjakan dan menunggu jawaban dari siswa lain. Siswa masih kesulitan dalam langkah-langkah pemecahan masalah yang benar. Berdasarkan penjabaran di atas, hal-hal tersebut dapat mengakibatkan kurang berkembangnya kemampuan pemecahan masalah siswa.

Hasil wawancara peneliti dengan seorang guru matematika SMP Salafiyah Darul Falah Mataram diperoleh informasi bahwa disamping metode pembelajaran yang digunakan adalah metode ceramah, guru juga melakukan berbagai altenatif lain seperti pemberian tugas-tugas serta menyelipkam beberapa permainan Matematika di dalam proses pembelajarannya. Selain itu diperoleh juga informasi bahwa siswa masih belum terbiasa dengan soalsoal pemecahan masalah dan umumnya mereka kurang mampu dalam menuliskan penyelesaiannya. Siswa belum mampu berpikir secara mandiri dalam memecahkan masalah sehingga mereka tidak percaya diri dalam menyelesaikan soal yang diberikan. Siswa juga masih dikatakan kurang dalam memecahkan masalah yang berkaitan dengan materi yang telah mereka pelajari.

Permasalahan tersebut tentunya harus dicarikan solusi guna membantu siswa dalam memecahkan permasalahan matematika. Salah satu solusi yang ditawarkan adalah dengan menerapkan model pembelajaran yang dapat merangsang siswa untuk lebih aktif dalam proses pembelajaran. Model pembelajaran yang dapat diterapkan untuk mengatasi permasalahan tersebut yaitu model pembelajaran kooperatif tipe Team Assisted Individualization (TAI), karena diasumsikan bahwa dengan diterapkannya model pembelajaran kooperatif tipe Team Assisted Individualization (TAI) dapat meningkatkan kemampuan siswa dalam menyelesaikan masalah Matematika.

Peneliti mencoba menerapkan model pembelajaran TAI dengan tujuan agar siswa belajar lebih aktif, lebih berpartisipasi dalam proses belajar mengajar, saling berbagi informasi dengan teman-temannya, serta mampu berinteraksi satu sama lain. Dengan model pembelajaran kooperatif tipe Team Assisted Individualization (TAI) lebih mengaktifkan proses belajar mengajar, serta terdapat hubungan timbal balik (interaksi) antara guru dengan siswa dan antara siswa dengan siswa yang lainnya.

Sesuai dengan uraian latar belakang di atas, maka peneliti mengangkat permasalahan tersebut untuk dilakukan penelitian dengan judul "Efektivitas Model Pembelajaran Team Assisted Individualization (TAI) terhadap Kemampuan Pemecahan Masalah Matematika Siswa Kelas VIII SMP Salafiyah Darul Falah Mataram.

\section{B. METODE PENELITIAN}

Dalam penelitian ini peneliti menggunakan pendekatan kuantitatif yaitu penelitian yang dilakukan dengan mengadakan percoban untuk menjelaskan hubungan antara variabel-variabel yang diselidiki. Desain penelitian yang digunakan adalah pre-eksperimen yaitu pemberian pretest dan postest untuk satu kelompok (OneGroup Pretest-Posttest Design). Desain ini menggunakan struktur desain:

TABEL 1

DESAIN PENELITIAN EKSPERIMEN DENGAN MODEL PREEKSPERIMEN

\begin{tabular}{|l|l|l|}
\hline Pretes & Variabel Terikat & Postes \\
\hline $\mathrm{O}_{1}$ & $\mathrm{X}$ & $\mathrm{O}_{2}$ \\
\hline
\end{tabular}

Dimana X merupakan perlakuan yang diberikan dan dilihat pengaruhnya dalam eksperimen tersebut, sedangkan $\mathrm{O}_{1}$ adalah pemberian pretest dan $\mathrm{O}_{2}$ adalah pemberian posttest. Dari tes inilah diambil kesimpulan (Juliansyah Noor, 2010: 115).

Penelitian ini dilaksanakan di SMP Salafiyah Darul Falah Mataram pada bulan Agustus 2017, dengan populasinya adalah siswa kelas VIII SMP Salafiyah Darul Falah Mataram tahun pelajaran 2017/2018 sebanyak 153 orang yang terdiri dari 5 kelas. Populasi dalam penelitian ini dapat dilihat pada tabel berikut:

TABEL 2

DATA POPULASI PENELITIAN SISWA KELAS KELAS VIII DI SMP SALAFIYAH DARUL FALAH

\begin{tabular}{|c|c|c|c|}
\hline No & Kelas & Jumlah Siswa & keterangan \\
\hline 1 & VIII A & 27 & Putri \\
\hline 2 & VIII B & 28 & Putri \\
\hline 3 & VIII C & 33 & Putra \\
\hline 4 & VIII D & 33 & Putra \\
\hline 5 & VIII E & 32 & Putra \\
\hline \multicolumn{2}{|c|}{ Total } & $\mathbf{1 5 3}$ \\
\hline
\end{tabular}


Adapun teknik pengambilan sampel (teknik sampling) yang digunakan pada penelitian ini yaitu Cluster Random Sampling. Teknik penarikan sampel dengan menggunakan metode ini adalah populasi dibagi dulu atas kelompok berdasarkan area atau cluster, lalu beberapa cluster dipilih sebagai sampel, dari cluster tersebut bisa diambil seluruhnya atau sebagian saja untuk dijadikan sampel, anggota populasi di setiap cluster tidak perlu homogen (Syofian Siregar, 2014: 59). Karena dalam populasi sampel sudah dalam bentuk kelompok (cluster), sehingga peneliti melakukan random kelas. Dengan demikian sampel dalam penelitian ini adalah 1 kelompok yang diambil secara acak dari 5 kelas. Setelah melakukan Cluster Random Sampling maka terpilih kelas VIII B SMP Salafiyah Darul Falah sebagai sampel dalam penelitian.

Teknik pengumpulan data yang digunakan dalam penelitian ini adalah tes, observasi, dan dokumentasi. Teknik tes digunakan untuk mengetahui kemampuan pemecahan masalah matematika siswa. Teknik observasi digunakan untuk Teknik observasi ini digunakan untuk memperoleh data tentang aktivitas belajar mengajar siswa. Aktivitas belajar mengajar siswa yang dimaksud yaitu kegiatan siswa dalam proses belajar mengajar dan juga untuk mengamati cara siswa didalam mengerjakan tugastugas yang diberikan oleh guru. Sedangkan teknik dokumentasi dilakukan untuk memperoleh data dalam pelaksanaan pembelajaran matematika. Data yang diambil berupa arsip/dokumen sekolah yang diperlukan untuk melengkapi data penelitian.Sementara itu bentuk tes yang digunakan berupa tes uraian (essay) dengan materi Sistem Persamaan Linear Dua Variabel (SPLDV).

\section{HASIL DAN PEMBAHASAN}

\section{Data Hasil Tes}

Hasil data yang diperoleh dari pretest dan posttest yang dianalisis dengan microsoft excel dan manual disajikan dalam tabel berikut:

TABEL 3

DESKRIPTIF DATA PEROLEHAN NILAI PRE TES DAN POST TES

\begin{tabular}{|c|l|c|c|}
\hline No & \multicolumn{1}{|c|}{ Deskriptif } & Pre test & Post test \\
\hline 1 & Jumlah & 1645 & 2156 \\
\hline 2 & Banyak data (n) & 28 & 28 \\
\hline 3 & Data minimum & 46 & 58 \\
\hline 4 & Data maksimum & 75 & 93 \\
\hline 5 & Rata-rata (mean) & 58,75 & 77,00 \\
\hline 6 & Standar deviasi (std) & 7,02 & 7,88 \\
\hline 7 & Varians & 49,31 & 62,15 \\
\hline 8 & Skor Ideal Minimum & 0 & 0 \\
\hline 9 & Skor Ideal Maksimum & 100 & 100 \\
\hline
\end{tabular}

\section{Analisis Data}

Analisis data yang digunakan dalam penelitian ini menggunakan analisis statistik yang berupa :

a. Uji Prasyarat

1) Uji Normalitas
Uji Normalitas dilakukan untuk mengetahui apakah data yang diperoleh dari lapangan berdistribusi normal atau tidak. Adapun pengujian normalitas data dilakukan dengan menggunakan rumus chi kuadrat $\left(\chi^{2}\right)$, yaitu:

$$
\chi^{2}=\sum_{i=1}^{k} \frac{\left(f_{0}-f_{h}\right)^{2}}{f_{h}}
$$

Keterangan:

$\chi^{2}=$ Nilai Chi-kuadrat

$f_{0}=$ Frekuensi Observasi

$f_{h}=$ Frekuensi Harapan

Dengan kreteria pengujian normalitasnya yaitu: Jika $\chi_{\text {hitung }}^{2} \geq \chi_{\text {tabel }}^{2}$, artinya data tidak terdistribusi normal.

Jika $\chi_{\text {hitung }}^{2}<\chi_{\text {tabel }}^{2}$ artinya data terdistribusi normal.

Adapun hasil perhitungan uji normalitas sebagai berikut:

TABEL 4

DATA HASIL UJI NORMALITAS

\begin{tabular}{|c|c|c|c|c|}
\hline \multirow{2}{*}{ Variabel } & \multicolumn{4}{|c|}{ Kai Kuadrat/Chi Kuadrat $\left(\chi^{2}\right)$} \\
\cline { 2 - 5 } & $\chi_{\text {hitung }}^{2}$ & $\begin{array}{c}\text { Signifikas } \\
i(a)\end{array}$ & Dk & $\chi_{\text {tabel }}^{2}$ \\
\hline Pretest & 1,45 & $5 \%$ & 3 & 7,81 \\
\hline Postest & 2,060 & $5 \%$ & 3 & 7,81 \\
\hline
\end{tabular}

Perhitungan uji normalitas secara manual dengan uji $\chi^{2}$ pada data hasil pretest diperoleh nilai $\quad \chi_{\text {hitung }}^{2}=$ 1,45 sedangkan untuk $\chi_{\text {tabel }}^{2}=7,81$ dengan $d k=3$ pada taraf signifikasi $(a)=5 \%$. Karena diperoleh nilai $\chi^{2}{ }_{\text {hitung }}<\chi_{\text {tabel }}^{2}$ yaitu $1,45<7,81$ maka data hasil pretest pada sampel penelitian berdistribusi normal. Sedangkan perhitungan uji normalitas secara manual dengan uji $\chi^{2}$ pada data hasil postest diperoleh nilai $\chi_{\text {hitung }}^{2}=2,060$ sedangkan untuk $\chi_{\text {tabel }}^{2}=7,81$ dengan $d k=3$ pada taraf signifikasi $(a)=5 \%$. Karena diperoleh nilai $\chi_{\text {hitung }}^{2}<\chi_{\text {tabel }}^{2}$ yaitu $2,060<7,81$ maka data hasil postest pada sampel penelitian berdistribusi normal.

2) Uji Homogenitas

Uji homogenitas dilakukan untuk mengetahui apakah variansi data dari sampel yang dianalisis homogen atau tidak. Peneliti menggunakan uji homogenitas Untuk mencari homogenitas varians sampel digunakan statistik uji-F dengan: 


$$
\mathrm{F}_{\text {hitung }}=\frac{\text { varians terbesar }}{\text { varians terkecil }}
$$

Dengan kriteria pengujian sebagai berikut:

Jika $F_{\text {hitung }} \geq \mathrm{F}_{\text {tabel }}$, berarti data tidak homogen.

Jika $\mathrm{F}_{\text {hitung }}<\mathrm{F}_{\text {tabel }}$, berarti data homogen

Adapun hasil perhitungan uji homogenitas sebagai berikut:

TABEL 5

DATA HASIL UJI HOMOGENITAS

\begin{tabular}{|c|c|c|c|c|}
\hline$F_{\text {hitung }}$ & $\begin{array}{c}\text { Signifika } \\
n s i(a)\end{array}$ & $d k_{\text {pembilang }}$ & $d k_{\text {penyebut }}$ & $F_{\text {tabel }}$ \\
\hline 1,26 & $5 \%$ & 27 & 27 & 1,93 \\
\hline
\end{tabular}

Hasil pengujian homogenitas dengan $a=5 \%$ dan $d k=27$, dengan perhitungan manual diperoleh nilai $F_{\text {hitung }}<F_{\text {tabel }}$ atau 1,26 $<1,93$ dengan kedua data penelitian merupakan data yang homogen.

\section{b. Uji Hipotesis}

Uji Hipotesis yang digunakan dalam penelitian ini adlah uji t-test, yaitu uji t-test sample releted. Uji $t$ test sample releted digunakan karena dalam peneliian ini peneliti menggunakan sampel berpasangan, dimana peneliti membandingkan sebelum dan sesudah perlakuan. Adapun rumus uji t-sampel related adalah sebagai berikut:

$$
t=\frac{\overline{X_{1}}-\overline{X_{2}}}{\sqrt{\frac{s_{1}{ }^{2}}{n_{1}}+\frac{s_{2}{ }^{2}}{n_{2}}-2 r\left(\frac{s_{1}}{\sqrt{n_{1}}}\right)\left(\frac{s_{2}}{\sqrt{n_{2}}}\right)}}
$$

Dimana;

$$
r=\frac{n\left(\sum X Y\right)-\left(\sum X\right)\left(\sum Y\right)}{\sqrt{\left[n\left(\sum X^{2}\right)-\left(\sum X\right)^{2}\right]\left[n\left(\sum Y^{2}\right)-\left(\sum Y\right)^{2}\right]}}
$$

\section{Keterangan:}

$\overline{X_{1}}=$ Rata-rata sampel 1

$\overline{X_{2}}=$ Rata-rata sampel 2

$\mathrm{S}_{1}$ = simpangan baku sampel 1

$\mathrm{S}_{2}=$ simpangan baku sampel 2

$\mathrm{S}_{1}^{2}=$ varians sampel 1

$\mathrm{S}_{2}^{2}=$ varians sampel 2.

Aturan keputusan :

Jika $-t_{\text {tabel }} \leq t_{\text {hitung }} \leq t_{\text {tabel }}$, maka $\mathrm{H}_{\mathrm{o}}$ diterima

Jika $t_{\text {hitung }} \geq t_{\text {tabel }}$ atau $-t_{\text {hitung }} \leq-t_{\text {tabel }}$, maka $\mathrm{H}_{\mathrm{o}}$ ditolak.
Berdasarkan hasil analisis yang diperoleh yaitu nilai $t_{\text {hitung }}=19,01$ dan $t_{\text {tabel }}=2,052$ untuk taraf signifikan $5 \%$ dengan $\mathrm{dk}=\mathrm{n}_{1}-1=27$. Sehingga berdasarkan kriteria pengujian hipotesis yaitu jika $t_{\text {hitung }} \geq t_{\text {tabel }}$ atau $t_{\text {hitung }} \leq-t_{\text {tabel }} \quad(19,01 \geq 2,052$ atau $-19,01 \leq-2,052$ ), maka $H_{o}$ ditolak dan $H_{a}$ diterima karena terdapat perbedaan secara signifikan.

\section{SIMPULAN DAN SARAN}

\section{Simpulan}

Kesimpulan yang dapat diambil berdasarkan hasil penelitian yang dilakukan peneliti adalah Model Pembelajaran Team Assisted Individualization efektif terhadap kemampuan pemecahan masalah Matematika siswa kelas VIII SMP Salafiyah Darul Falah Mataram tahun pelajaran 2017/2018. Hal ini dibuktikan dari hasil analisis data yang menunjukkan bahwa nilai hasil pretest dan postes dengan uji $t$ Sampel Related diperoleh $t_{\text {hitung }}=$ 19,01 dan $t_{\text {tabel }}=2,052$ untuk taraf kesalahan 5\% dan $\mathrm{df}=27$. Sehingga berdasarkan kriteria pengujian hipotesis yaitu jika $t_{\text {hitung }} \geq t_{\text {tabel }}$ atau $t_{\text {hitung }} \leq-t_{\text {tabel }}$ atau

$(19,01 \geq 2,052$ atau $-19,01 \leq-2,052)$, maka $H_{o}$ ditolak karena terdapat perbedaan secara signifikan. Hal ini menunjukkan bahwa Model Pembelajaran Team Assisted Individualization efektif terhadap kemampuan pemecahan masalah Matematika siswa kelas VIII SMP Salafiyah Darul Falah Mataram tahun pelajaran 2017/2018.

\section{Saran}

a. Bagi siswa. Kepada siswa SMP Salafiyah Darul Falah Mataram hendaknya selalu mengembangkan kemampuan pemecahan masalah matematika untuk mempermudah dalam pembelajaran matematika.

b. Bagi guru. Kepada guru, khususnya guru mata pelajaran matematika dalam melaksanakan kegiatan pembelajaran hendaknya meningkatkan penggunaan metode pembelajaran yang berbasis masalah untuk meningkatkan kemampuan pemecahan masalah siswa.

c. Bagi peneliti. Bagi para peneliti selanjutnya yang berkenan ingin melakukan penelitian yang sama, skripsi ini dapat dijadikan bahan pertimbangan dalam mengembangkan penelitian yang berhubungan dengan variabelvariabel yang mempengaruhi kemampuan pemecahan masalah matematika dan variabel lain dalam cakupan yang luas. 


\section{DAFTAR RUJUKAN}

Arikunto, Suharsimi. Dasar-dasar Evaluasi Pendidikan Edisi 2.

Astuti, Alfira Mulya. Statistika Penelitian. Mataram: Insan Madani Publishing, 2015.

Hadi, Sutarto, dan Radiyatul. "Metode Pemecahan Masalah Menurut Polya Untuk Mengembangkan Kemampuan Siswa Dalam Pemecahan Masalah Matematis Di Sekolah

Menengah Pertama". EDU-MAT Jurnal Pendidikan Matematika, Vol . 2 No. 1. Februari, 2014.

Hamdayana, Jumanta. Model dan Metode Kreatif dan Berkarakter. Bogor: Ghalia Indonesia, 2014.

Huda, Miftahul. Model-Model Pengajaran dan Pembelajaran. Yogyakarta: Pustaka Pelajar, 2016.

Lestari, Karunia Eka dan Muhammad Ridwan Yudhanegara. Penelitian Pendidikan Matematika. Bandung: PT Refika Aditama, 2017.

Ngalimun. Strategi dan Model Pembelajaran . Sleman Yogyakarta: Aswaja Pressindo, 2016.

Noor, Juliansyah. Metodologi Penelitian. Jakarta : Prenada Media Group, 2010.

Ramayulis. Metodologi Pendidikan Agama Islam. Jakarta: Kalam Mulia, 2012

Rusman. Model-Model Pembelajaran Mengembangkan Profesionalisme Guru . Jakarta: PT Raja Grafindo Persada, 2012.

Sanjaya, Wina. Strategi Pembelajaran Berorientasi Standar Proses Pendidikan. Jakarta: Kencana, 2011.

Siregar, Syofian. Statistika Deskriptif untuk Penelitian. Jakarta : PT Raja Grafindo Persada, 2010.

Siregar, Syofian. Statistik Parametrik Untuk Penelitian Kuantitatif. Jakarta: PT. Bumi Aksara, 2014.

Slavin, Robert E. Cooperative Learning. Bandung: Nusa Media, 2005.

Sugiyono. Metode Penelitian Pendidikan (Pendekatan Kuantitatif, Kualitatif, R\&D). Bandung: CV Alfabeta, 2015.

Sri Sumartini, Tina. "Peningkatan Kemampuan Pemecahan Masalah Matematis Siswa melalui Pembelajaran Berbasis Masalah". Jurnal Pendidikan Matematika STKIP Garut, Vol. 8, No.3. April, 2016.

Sutarto dan Syarifudin. Desain Pembelajaran Matematika. Yogyakarta: Samudra Biru, 2013.

Trianto. Mendesain Model Pembelajaran Inovatif-Progresif: konsep, Landasan, dan Implementasinya pada Kurikulum Tingkat Satuan Pendidikan (KTSP). Jakarta: Kencana, 2012.

Wardhani, Sri. Analisis SI dan SKL Analisis SI dan SKL Mata Pelajaran Matematika SMP/MTs untuk Optimalisasi Tujuan Mata Pelajaran Matematika. Yogyakarta: Pusat Pengembangan dan Pemberdayaan Pendidik Dan Tenaga Kependidikan Matematika, 2008. 